\title{
Retratos da comunicação em saúde: desafios e perspectivas
}

\author{
Communication frames on health: challenges and perspectives \\ Retratos de la comunicación en salud: desafíos y probalidades
}

Tânia Montoro ${ }^{1}$

\section{E por falar em Comunicação na Saúde}

O artigo da pesquisadora Maria Ligia Rangel é instigador pela atualidade do olhar sobre a temática e enriquecedor pela capacidade de sublinhar questões estruturais, que se colocam como desafios para o universo da pesquisa em comunicação e saúde especialmente, quanto ao papel estratégico da comunicação no controle do dengue no país. Orienta-se o trabalho de Rangel para duas indagações centrais:

a) Quais os problemas relativos às práticas de educação, comunicação e participação comunitárias no controle do dengue?

b) Como as práticas de comunicação e educação vêm sendo realizadas para o controle do dengue no Brasil?

Elegendo o conceito de comunicação como cultura, como arena, em que se efetiva à experiência do debate público na polis, e vinculando ao conceito de comunicação em saúde o(s) significante(s): "[...] troca, interação, intersubjetividade, diálogo, expressão, configurando a comunicação com múltiplas dimensões, que vão desde sua condição fisiológica, que envolve audição, as sensações, a visão, para alcançar as dimensões afetiva, cognitiva, sóciocultural e tecnológica" (p.433), o esforço analítico/crítico do trabalho enriquece o debate, ao colocar, de forma sistematizada, resultados de pesquisas qualitativas, realizadas por diferentes matrizes teóricas/metodológicas, sobre práticas de comunicação e informação utilizadas para prevenção do dengue. Estas práticas comunicacionais, traduzidas em mensagens, são repassadas às comunidades por meio de mídia de massa e pelos profissionais de saúde que fazem a intermediação entre o serviço e o usuário, o cidadão e o Estado - no desenvolvimento de uma política publica universalizada - e o consumidor e o produto, dentro de uma visão mercadológica de saúde.

Com o intento de pontuar os elementos discursivos fundantes e convergentes no conjunto das ações estratégicas de intervenção em comunicação, educação e participação na prevenção do dengue, a autora destaca a categoria analítica de "modelo" com objetivo de estudar as relações entre um conjunto de variáveis com base nas quais são retiradas implicações ou previsões de determinado fenômeno social.

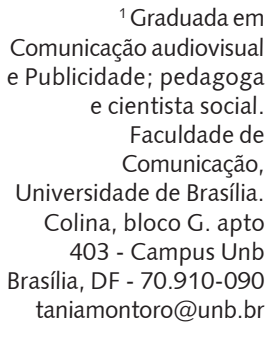

Comunicação audiovisual idade; pedagoga cientista social. Faculdade de Comunicação, Colina, bloco G. apto ília DF - 70.910-090 taniamontoro@unb.br 
Um modelo constitui basicamente uma estrutura analítica com objetivo de descrever vários aspectos e dimensões da realidade que é tão complexa que se torna necessário simplificar e usar abstrações para se alcançar algum progresso em sua compreensão (Gross, 2004, p.19)²
2 tradução de Armando Bulcão, Tânia Montoro e Lavina Madeira.

Partindo da noção sociológica de modelo, Rangel seleciona os seus objetos de reflexão:

- qual o modelo de comunicação que fundamenta as práticas de comunicação e educação na prevenção do dengue?

- qual o modelo explicativo de saúde e doença presente nas mensagens?

- qual o modelo de prevenção utilizado?

- qual o modelo de participação social na relação estado/ sociedade?

Diante de uma apreciação crítica da prática da comunicação, educação e participação em saúde na prevenção do dengue, o trabalho conclui que o modelo de comunicação adotado por diferentes agentes e por uma pluralidade de mensagens ancora-se em um:

[...] modelo de comunicação que se caracteriza, portanto por ter cunho campanhista, pontual, descontínuo, com ênfase em situações epidêmicas, quando seria necessário que o dengue estivesse na pauta da mídia durante todo o ano, assim como que nas mídias alternativas, aquelas produzidas pelo próprio serviço e se encontrassem respostas às duvidas mais freqüentes, de forma correta e precisa. (p. 436)

Em consonância com o estudo de Rangel, em trabalho de pesquisa recente (Montoro, Bulcão, 2006-2007), investigando a percepção dos gestores dos SUS em relação ao papel da comunicação e educação em saúde, entrevistamos 64 gestores de saúde, em diferentes unidades da federação, e pudemos observar que distintas matrizes teóricas fundamentam a compreensão do que seja comunicação em saúde.

Observa-se que há concepções diferentes sobre o papel e fundamento mesmo da comunicação em saúde, que vai desde o paradigma clássico da comunicação para o desenvolvimento, que se baseia na construção de um modelo de comportamento saudável transposto e imposto de um país desenvolvido para um subdesenvolvido; passando pela comunicação para promoção da saúde em que se enfatiza o repasse de informação e a promoção de conhecimentos, como valiosos instrumentos para participação e as mudanças dos estilos de vida nas comunidades, chegando à comunicação estratégica em que a comunicação para saúde só pode ser atingida pelo estabelecimento de uma interdependência sistêmica da comunicação com a tecnologia da informação.

Esta polissemia, com relação à definição do que se compreende por comunicação em saúde para prevenção e promoção, impacta a possibilidade de se visualizar modelo único de comunicação nas práticas de intervenção, na medida em que, produz um emaranhado discursivo de estratégias e práticas chamadas de "comunicação para mobilização social", "comunicação e marketing social em saúde", "comunicação e advocacy midiática", "comunicação para mudança social", "comunicação e educação em saúde", entre outros. Não fossem somente diferenças conceituais e de estratégias de intervenção, este emaranhado discursivo/conceitual, permite que mesmo os profissionais de comunicação em saúde confundam comunicação institucional (realizada pelos governos para promover o Ministério da Saúde e suas secretarias/ institutos e fundações) com 
campanhas de prevenção de doenças e, assim, passam a esperar as diretrizes dos órgãos centrais para fundamentar suas atividades e ações.

O calendário anual de saúde constitui o aspecto mais visível do planejamento das ações de comunicação em saúde. É identificado, pela pesquisa, como aspecto mais aparente da existência de uma matriz de planejamento. A existência de datas nacionais constitui um fator que favorece a integração dos campos de atuação dos diferentes gestores (político, técnico e de comunicação), nas três esferas do SUS.

Como pano de fundo, nota-se a presença de conceitos orientadores, oriundos de campos, correntes teóricas na saúde (programa universal de atenção à saúde), da governança privada (planejamento estratégico) e da comunicação social (mobilização social).

Numa síntese, dois fragmentos discursivos dos conteúdos levantados na pesquisa resumem questões de princípio, expressas no discurso dos gestores, considerados aqui na condição de sujeito coletivo: "As ações de comunicação não podem resolver e não resolvem à ausência ou falhas na execução de políticas públicas permanentes". Ou, ao revés: "Sem uma política pública, que alcance e integre as três esferas do sistema de saúde, não há como planejar uma boa comunicação".

Verificou-se também que ações de comunicação têm por base a logística das ações de saúde - a produção de vacinas, a distribuição, a mobilização de agentes de saúde, etc. - mas nem sempre consideram a logística da comunicação.

Além de dificuldades financeiras e operacionais, apontadas como empecilhos a uma maior participação, identifica-se um sistema de comunicação no qual o fluxo da informação é bem mais intenso e sistemático no sentido vertical, de cima para baixo (ministério, estados, municípios), e raro e assistemático no sentido inverso (municípios, estados, ministério).

Os discursos refletem a ausência e a demanda por canais de comunicação direta, que favoreçam um fluxo de informação mais equilibrado, no sentido inverso da perspectiva federal, desde os município e estados, interligando gestores de comunicação em seus respectivos campos de atuação e competências. Uma rede, não apenas no sentido tecnológico, mas sobretudo no sentido de promover a interação direta entre gestores - uma comunicação de caráter interpessoal, vista como condição necessária e indispensável ao planejamento integrado de ações nacionais e regionais descentralizadas de comunicação em saúde.

$\mathrm{Na}$ esfera federal, o planejamento das ações de comunicação é centralizado em departamentos e setores especializados (Assessoria de Comunicação e Núcleo de Comunicação), que efetivamente realizam as tarefas de planejamento de comunicação e de mediação entre mídia, agências de publicidade, gestores político-administrativos e gestores e técnicos de saúde do Ministério.

Os gestores federais, estaduais e municipais expõem com freqüência a necessidade de um planejamento de longo prazo, de ações contínuas, pactuadas, a serem executadas nos momentos em que não há riscos ou crises. E de um planejamento eficaz para enfrentar as situações de risco e de crise - uma situação cotidiana, que inviabiliza inclusive o próprio planejamento, segundo relatos de gestores federais e municipais de comunicação.

Há uma percepção difusa de que ações de saúde e ações de comunicação concorrem no orçamento. Revela-se uma compreensão comum aos gestores: as ações de comunicação, ainda que avaliadas como importantes e fundamentais para o êxito, são freqüentemente pensadas, planejadas orçadas, monitoradas e avaliadas de modo quase intuitivo, como complementares, acessórias e exteriores às ações de saúde - estas sim, indispensáveis.

É seguindo tal raciocínio, que os conteúdos discursivos dos gestores revelam certa tendência de não incluir os gestores de comunicação em todas as etapas, do planejamento à execução e avaliação, das ações de saúde. E vice-versa nas ações de comunicação. Por conseqüência, se por um lado, a participação do técnico de saúde no planejamento de ações da comunicação é por vezes consultiva e abrange apenas algumas etapas; por outro, a participação dos técnicos de comunicação no planejamento das ações de saúde possui também natureza consultiva e restrita a determinadas instâncias e etapas.

Não obstante, depreende-se da análise, a compreensão prática de que tais limites e diferenças conceituais tornam-se abstratos e imprecisos, no trabalho de campo. No relato acerca da execução de 
eventos e campanhas, percebe-se que as ações de comunicação e ações de saúde se entrelaçam e se fundem de modo indistinto, como se fossem a mesma face da mesma moeda.

Conclui-se que, na execução, e bem antes, durante o planejamento, ações de saúde podem e devem ser pensadas como ações de comunicação e vice-versa.

A preocupação de envolver, no planejamento da comunicação, a sociedade civil e os movimentos sociais organizados, por meio de instâncias institucionais formais e informais, é manifesta no discurso de diferentes gestores, ainda que ponderem que muitas instâncias participativas (federais, estaduais e municipais), por vezes, carecem de representatividade.

Nota-se a ausência de uma rede de comunicação direta, estável e permanente que integre, horizontal e verticalmente, a atuação de gestores de comunicação, na função de mediadores da relação imprensa, agências de publicidade, gestores político-administrativos, gestores técnicos de saúde.

Como resultado, com base na observação dos problemas enfrentados pelos gestores, é possível evidenciar empecilhos e dificuldades à implantação de uma cultura de planejamento da comunicação em saúde, resumidos a seguir:

A logística das ações de comunicação: No âmbito federal, as deficiências na coordenação temporal e logística acarretam freqüentes atrasos na distribuição, para estados e municípios, de materiais de campanha e impressos produzidos pelo governo federal, o que acaba por inviabilizar sua utilização. Como resultado, no planejamento anual, vários gestores estaduais e municipais não consideram a utilização do material de campanha produzido pela esfera federal, optando pela produção de materiais regionais, tendo, como conseqüência, a redundante superposição de conteúdos e o desperdício de material. Paradoxalmente, estes problemas logísticos surgem também como estímulo e oportunidade para o planejamento de campanhas e materiais regionais e locais.

Capacidade dos quadros: No âmbito estadual e municipal, de acordo com vários gestores, a implantação de uma cultura de planejamento estratégico da comunicação defronta-se com a incapacidade e a carência de quadros profissionais - comunicadores, jornalistas, publicitários notadamente, nos estados e municípios. Uma incapacidade percebida pelo gestor como relacionada à estrutura dos órgãos públicos, imersos no interior de uma cultura burocrática e lenta. Aponta-se a necessidade de investimento na aquisição e formação de recursos humanos especializados.

Descontinuidade das ações: as ações de comunicação realizadas nas diferentes esferas carecem de políticas públicas permanentes que assegurem a continuidade das ações, transcendendo fatores conjunturais e políticos - condição tida como indispensável para um planejamento de longo prazo.

O papel da comunicação: de modo geral, as atividades de comunicação são pensadas como acessórias às ações de saúde. Ao contrário, em muitos casos, especialmente nos momentos de crise, espera-se que a comunicação seja capaz de solucionar por si problemas estruturais.

Incapacidade de atender à demanda cotidiana: as ações de comunicação são orientadas pelas demandas cotidianas da mídia. Tais demandas, freqüentemente, carreiam toda a capacidade produtiva dos gestores de saúde e de comunicação, inviabilizando qualquer planejamento, seja a curto, médio ou longo prazo. Tal panorama é particularmente descrito nas situações de crise.

Falta de representatividade das instâncias: as instâncias participativas, por vezes, carecem de representatividade, e requerem a presença efetiva de representantes por parte do governo e da sociedade civil.

Ausência de dados: o planejamento de ações de comunicação em muitos casos carece de uma memória institucional e de dados de monitoramento e avaliação, especialmente no que diz respeito à eficácia das campanhas publicitárias realizadas em anos anteriores. Não há avaliações sistemáticas que possam apontar elementos de linguagem, conteúdo, forma, entre outros, que permitam um melhor uso das mensagens e o aumento de impacto delas sobre o público (prioritário) a que se destina. Também não há avaliação de custo - beneficio entre os gastos de campanha e a eficácia delas para prevenção de doença e promoção da saúde.

A dissociação entre planejamento de saúde e de comunicação é particularmente evidente em alguns extratos do discurso dos gestores: "O planejamento logístico das ações de saúde antecede o planejamento de ações de comunicação"; "O planejamento de comunicação não faz parte do planejamento de ações de saúde dos gestores técnicos". 
Em relação aos meios de comunicação de difusão das mensagens, evidencia-se, na percepção dos gestores do sistema, um deslumbramento com a mídia de massa, em especial a televisão. Seja por noticias, propagandas, publicidade e merchandising, a mídia televisão tem a preferência dos gestores para educar e informar. Entretanto a literatura (Henriques, 2004; Werneck, Toro, 1996) mostra que quanto maior a cobertura do meio de comunicação, menor sua efetividade. Por buscar a efetividade, a comunicação e educação em saúde, deveria dar especial atenção a uma comunicação de menor cobertura e maior impacto. Autores como Pope e Mays (2006) salientam que a comunicação para prevenção em saúde, como um processo amplo, não depende, para ser bem-sucedida, apenas da simples difusão de informações, como muitos são levados a acreditar, muito embora a visibilidade, a divulgação e a presença na mídia sejam elementos decisivos. É necessário um esforço permanente para colocar as questões principais no campo dos valores, dos elementos simbólicos com os quais as comunidades operam em constante atenção para com os múltiplos significados que orientam a vida das comunidades, esforço tal que os grupos constituídos para ação e suas lideranças podem empreender estrategicamente. Para garantir uma maior efetividade, a comunicação dirigida deve ser adotada cotidianamente. Ela tem por finalidade transmitir e conduzir informações, estabelecendo uma comunicação orientada e freqüente com o público identificado. Como estratégia de comunicação dirigida, a interação face a face retoma os contextos interativos de co-presença, promovendo uma maior proximidade entre os indivíduos, possibilitando ações mais coesas.

Por último, é importante sublinhar que as práticas de comunicação em saúde devem se constituir em estratégias de promoção da saúde e serem mobilizadoras de ações intersetoriais, conforme propõe, com pertinência, Rangel. Adotando um caráter educativo, a comunicação deve gerar referenciais para a ação e para mudanças de atitudes e mentalidades nos indivíduos. No dizer de Braga (2001), é uma comunicação diversificada, pessoalizada, necessariamente local e de inserção cultural e etnoorientada.

\section{Referências}

BRAGA, J.L. Aprendizagem versus educação na sociedade mediatizada. In: ENCONTRO ANUAL DA ASSOCIAÇÃO NACIONAL DE PROGRAMAS DE PÓS-GRADUAÇÃO EM COMUNICAÇÃO, COMPÓS, 10., 2001, Brasília. Anais... Brasília: GT Comunicação e Sociabilidade, 2001

GROSS, A. The rethoric of science. Cambridge: Havard University Press, 2004.

HENRIQUES, M.S. Comunicação e estratégias de mobilização social. 2.ed. Belo Horizonte: Autentica, 2004.

MONTORO, T.; BULCÃO, A. Relatório de pesquisa. Gestão da comunicação aplicada à vigilância em saúde: a percepção dos gestores. Brasília: Pós-graduação da Faculdade de Comunicação da Universidade de Brasília, 2006-2007.

POPE, C.; MAYS, N. (Orgs.). Qualitative research in health care. London: Blackwell Publishing, 2006.

WERNECK, N.; TORO, B. Mobilização social: uma teoria para universalização da cidadania. In: MONTORO, T. (Org.). Comunicação e mobilização social. Brasília: Editora UnB, 1996. p.24-32. 